\title{
Influence of Fibrinogen on
}

\section{Staphylococcus epidermidis}

\section{Adhesion can be Reversed by Tuning}

\section{Surface Nanotopography}

Hulander, Mats; Valen-Rukke, Håkon; Sundell, Gustav; Andersson, Martin

Number of pages: 10

Number of images: 10

Supporting information

\section{SI1}

Preparation of gradient surfaces

A schematic overview explaining the process of preparing gradient surfaces is shown below. Briefly, an APTES functionalized glass surfaces was immersed in a MilliQ $\mathrm{SiO}_{2}$ nanoparticle colloid solution. A high molar solution of sodium citrate buffer was then carefully inserted in the bottom of the container. Over time, diffusion of the buffer will create a gradient in ionic strength, changing the electrostatic screening of the charged colloids, thereby dictating the distance between the particles upon binding to the APTES functionalized surface. Details of the procedure can be found in ${ }^{1-2}$

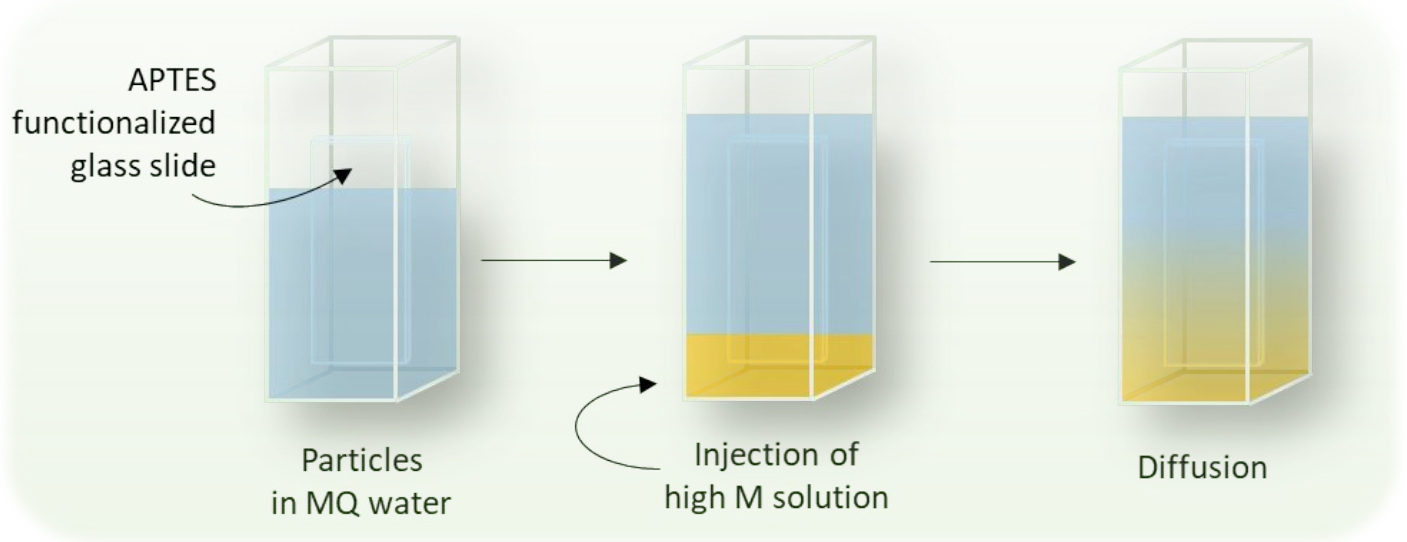




\section{$\mathrm{SI} 12$}

\section{Water contact angle measurements on PEG functionalized gradients}

Water contact angle measurements were performed to confirm the presence of PEG between the nanoparticles. Experiments were performed on a manual goniometer (Rame'Hart) using $5 \mu \mathrm{l}$ droplets of distilled water.

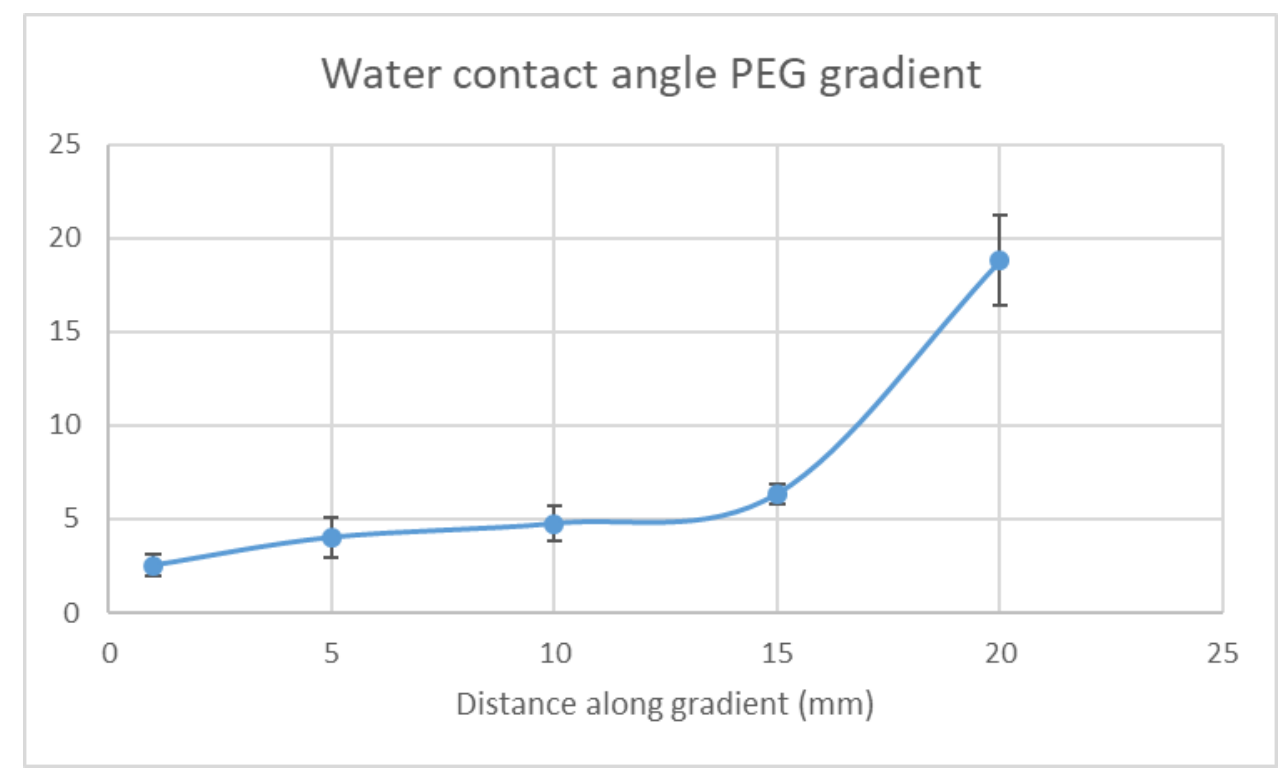

Figure SI2. Water contact angle measurements along a PEG functionalized gradient. The gradual increase in PEG along the gradient is reflected on the CA. Note the sharp increase in CA after $15 \mathrm{~mm}$ where the gradient ends and the smooth control surface starts. 


\section{SI3}

\section{XPS}

XPS measurements along the gradient surfaces was performed before and after heat-treatment of the gradient at $400^{\circ} \mathrm{C}$ for $60 \mathrm{~min}$. The heat-treatment was performed in order to remove the remaining ATPES between the nanoparticles.

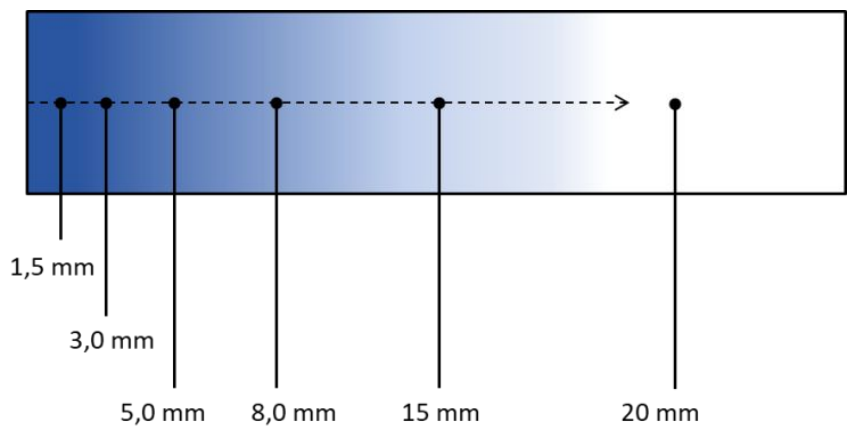

Figure SI3.1. Schematic of six sampling positions for XPS measurements along the gradient. Highest nanoparticle density is to the left. Position $20 \mathrm{~mm}$ is smooth control surface.

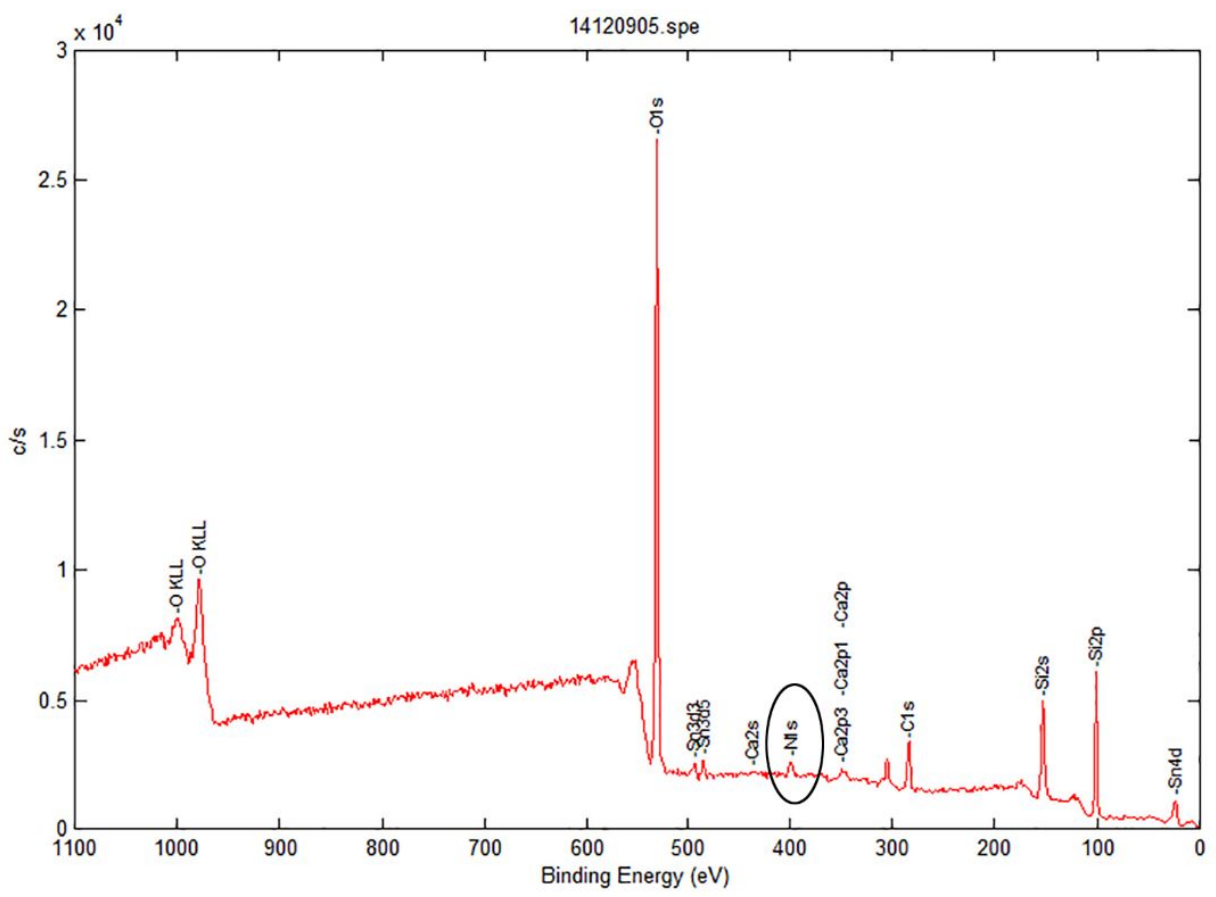

Figure SI3.2. Example of XPS measurement on a non-heat-treated gradient surface taken at position $5 \mathrm{~mm}$ (see Fig. SI3.1)). The presence of amines from APTES is evident as a Nitrogen peak at $400 \mathrm{eV}$ (circled). 


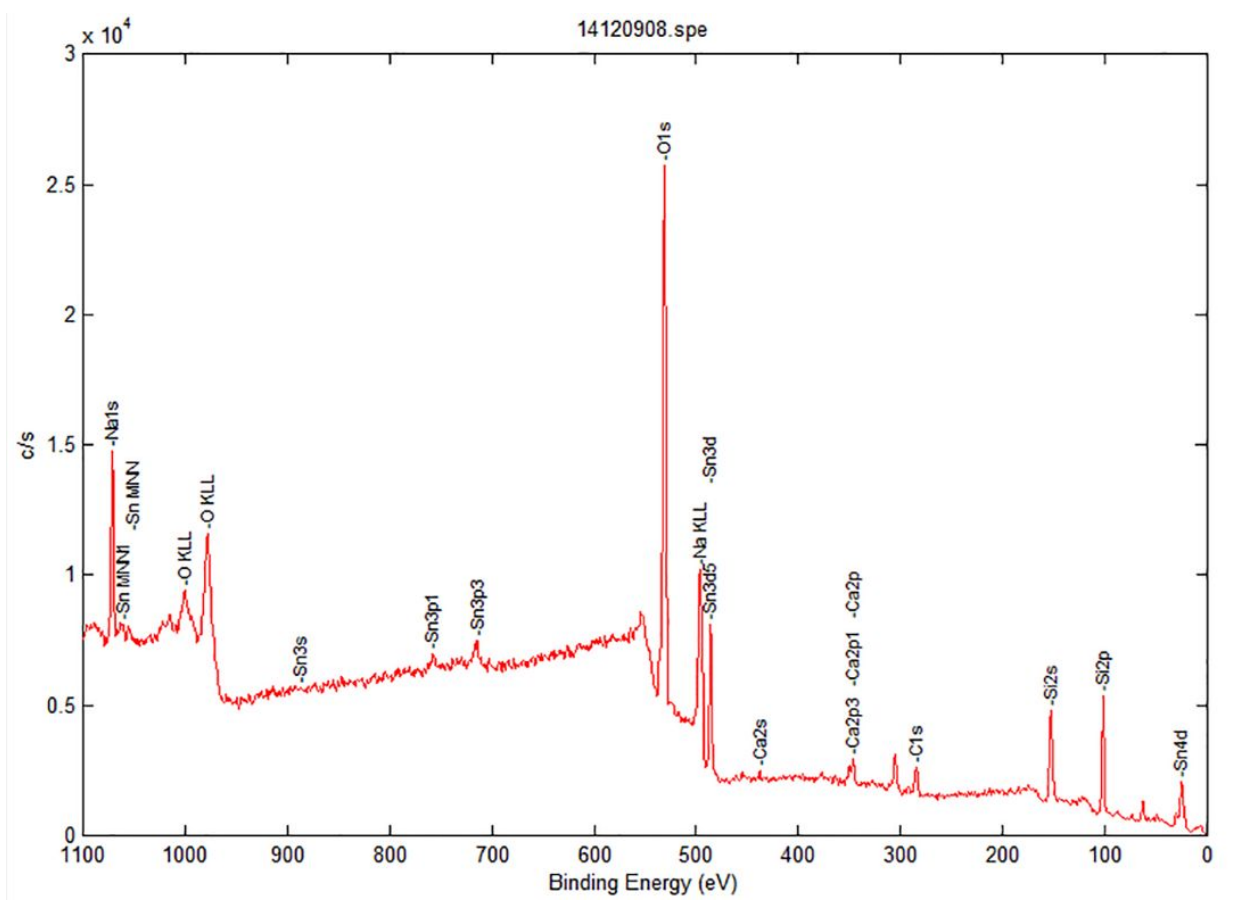

Figure SI3.3. Example of XPS measurement on a heat-treated gradient surface $\left(400^{\circ} \mathrm{C}\right.$ for $\left.60 \mathrm{~min}\right)$ taken at position $5 \mathrm{~mm}$ (see Fig. S13.1). Note the missing Nitrogen peak at $400 \mathrm{eV}$, confirming complete removal of amines from the ATPES functionalization. 


\section{$\mathrm{SI} 4$}

\section{Flow chamber details}

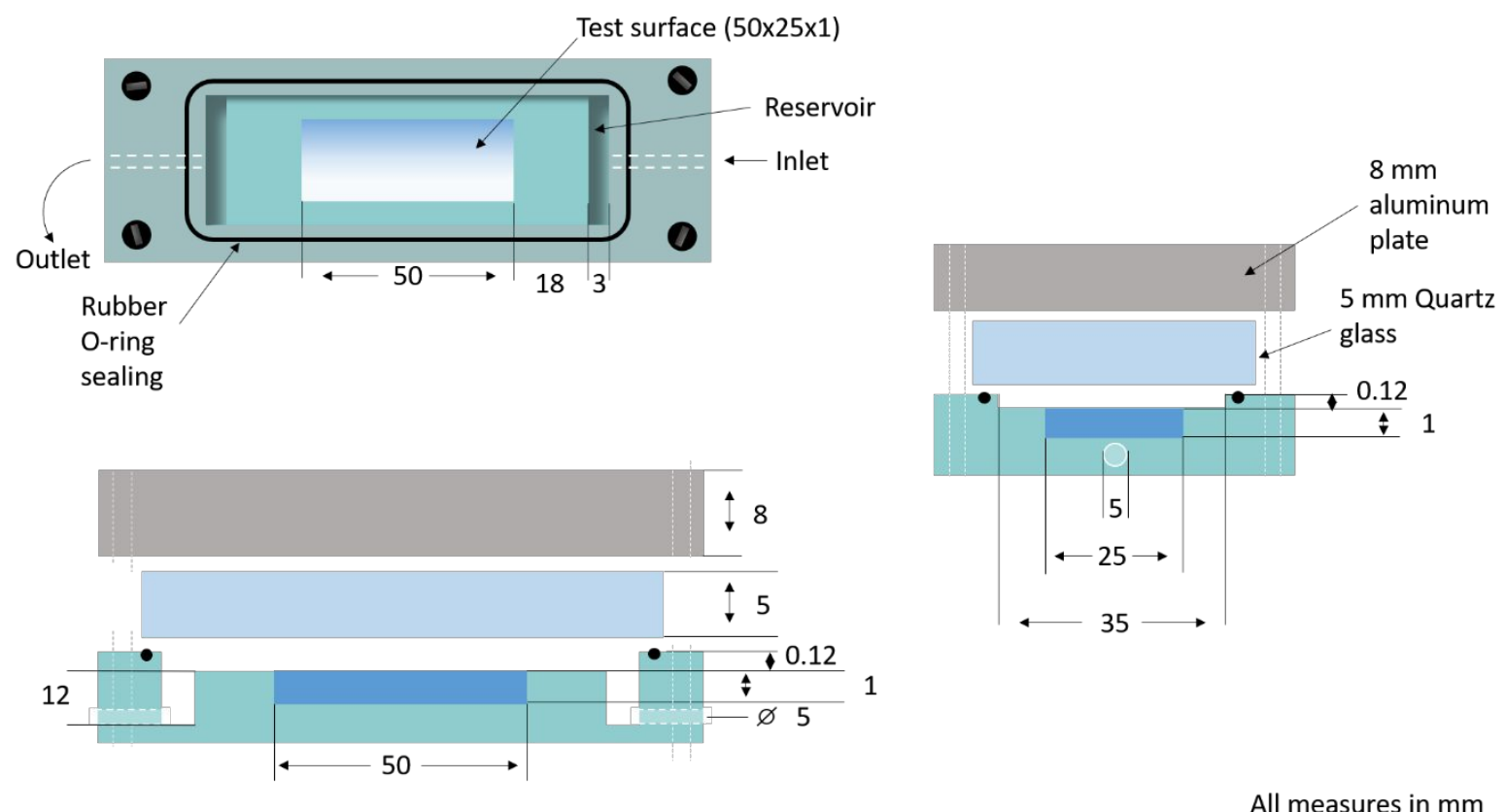

Figure SI4. Schematic of the parallel plate flow chamber used for the experiments. 


\section{SI5}

Image analysis

Bacteria were counted using a simple script that was run in the free software ImageJ. The original photo was cropped to avoid artefacts from vignetting during the aoutomated counting. The number of bacteria was then counted using the "find maxima" feature in the program, using a noise threshold of 12 . The script is seen below:

path=File.directory+File.name;

print(i+", "+getTitle);

makeRectangle(1000, 500, 2000, 2000);

run("Crop");

run("Find Maxima...", "noise=12 output=Count"); 


\section{Si6}

\section{QCM measurement of fibrinogen mass adsorption}

Silicon dioxide QCM sensors (Biolin Scientific, Sweden) were cleaned in $99.5 \%$ ethanol for 30 min on an ultrasonic bath, followed by rinsing in $\mathrm{MQ}$ water and blow drying with gaseous nitrogen. Sensors were then left for $1 \mathrm{~h}$ in an UV/O3 cleaning chamber and then amine functionalized with APTES, using the protocol described in the main article. On half of the sensors, $\mathrm{SiO}_{2}$ nanoparticles $(40 \mathrm{~nm})$ were immobilized by immersing the sensors in a solution of $5 \mathrm{mM}$ sodium citrate buffer at $\mathrm{pH} 4$ containing $\sim 6 \times 10^{-9} \mathrm{M}$ of nanoparticles for $15 \mathrm{~min}$ to achieve a monolayer surface coverage of nanoparticles of around $40 \%$, corresponding to $~ 350$ particles per $\mu \mathrm{m}^{2}$ exampled in the SEM micrograph in Fig. SI6a.

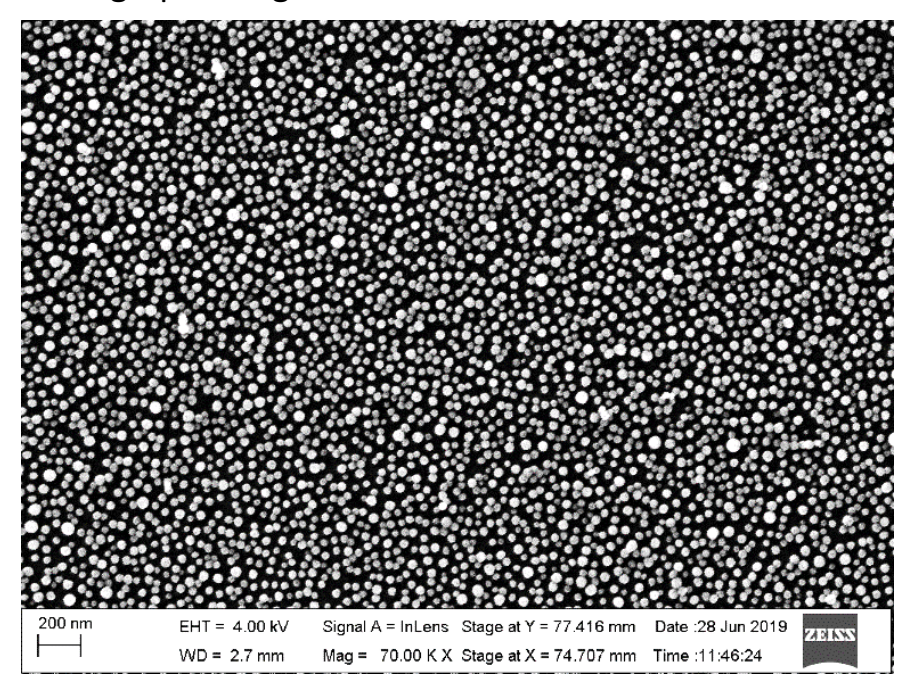

Figure SI6a: SEM micrograph of silicon dioxide nanoparticles adsorbed to a $\mathrm{SiO}_{2}$ QCM sensor from a $5 \mathrm{mM}$ buffer of sodium citrate at $\mathrm{pH}$ 4. Image was recorded post fibrinogen adsorption.

All sensors were heat-treated at $400{ }^{\circ} \mathrm{C}$ for $1 \mathrm{~h}$ to remove any residual amine functionalization and then used directly for the QCM measurements.

After $5 \mathrm{~min}$ of stable baseline with phosphate buffer $(10 \mathrm{mM})$, a $100 \mu \mathrm{g} / \mathrm{ml}$ solution of human fibrinogen dissolved in the same buffer was injected. After $60 \mathrm{~min}$ of adsorption, a $10 \mathrm{~min}$ rinse with phosphate buffer was again performed. Measurements were performed at room temperature $\left(22^{\circ} \mathrm{C}\right)$ and were repeated three times on two different occasions. 


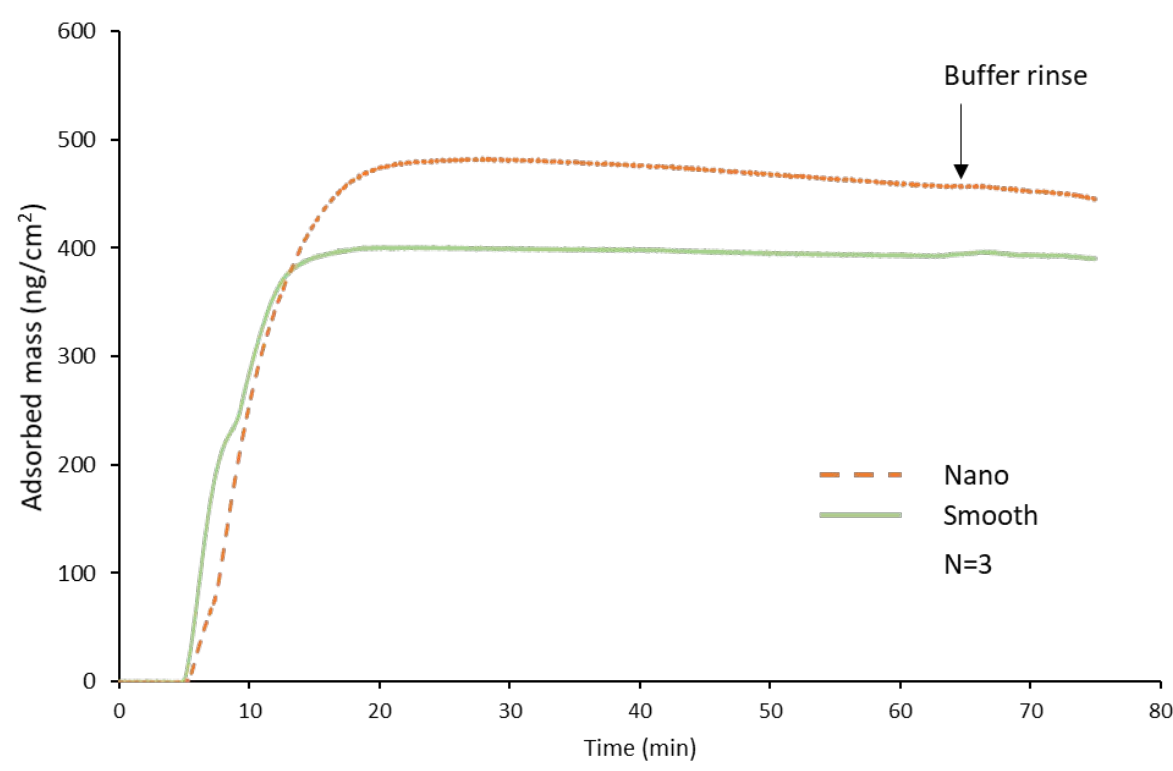

Figure SI6b: Adsorbed mass from a $100 \mu \mathrm{g} / \mathrm{ml}$ human fibrinogen solution on smooth and nanostructured $\mathrm{SiO}_{2}$ QCM sensors monitored at the $3^{\text {rd }}$ overtone. Measurements show averages from 3 individual experiments. 


\section{SI7}

\section{Additional control measurement}

To ensure that the observed adhesion pattern of S. epidermidis was a consequence of the number of nanoparticles on the surface and not caused by irregularities in the flow in the chamber, a plain hydrophilic glass slide without nanoparticles was pre-treated with fibrinogen $(100 \mu \mathrm{g} / \mathrm{ml})$ for $60 \mathrm{~min}$ before bacteria $\left(\mathrm{OD}_{600} 1.5\right)$ was incubated for $10 \mathrm{~min}$ and then subjected to a flow of $1.4 \mathrm{~ms}^{-1}$.

\section{Bacterial count on smooth control surface}

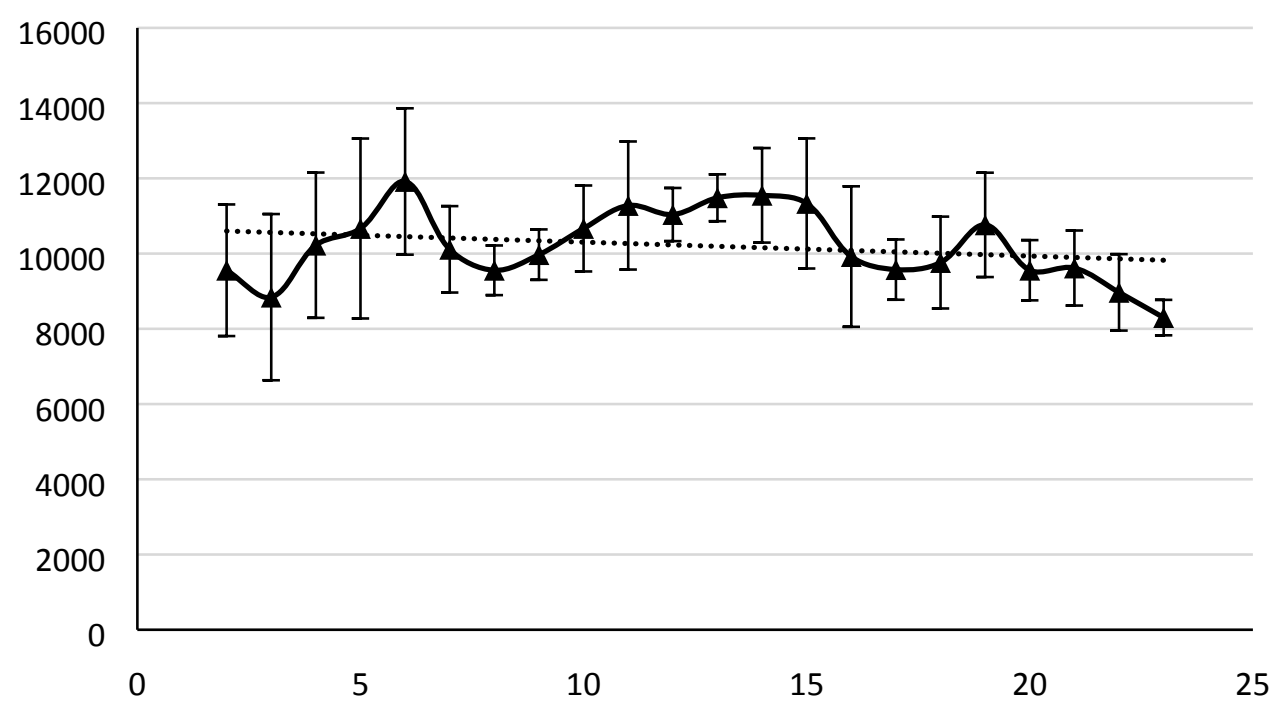

Figure SI7. Number of counted bacteria per $\mathrm{mm}^{2}$ on a smooth microscope glass slide pretreated with human fibrinogen and mounted in the flow chamber. Bacteria were incubated for $600 \mathrm{~s}$ and then subjected for a flow of $1.4 \mathrm{~ms}^{-1}$. 


\section{SI8}

\section{Bacterial footprints}

Proteinous residues left behind on the surface by cells being washed off by the flow in the flow chamber were analyzed for size and displayed in the graph SI8 below. In total, 35 residues were manually analyzed. Two clear populations were found that we interpret as a representation of cells being attached as single or duplex.

\section{Footprint area $\left(\mathrm{nm}^{2}\right)$}

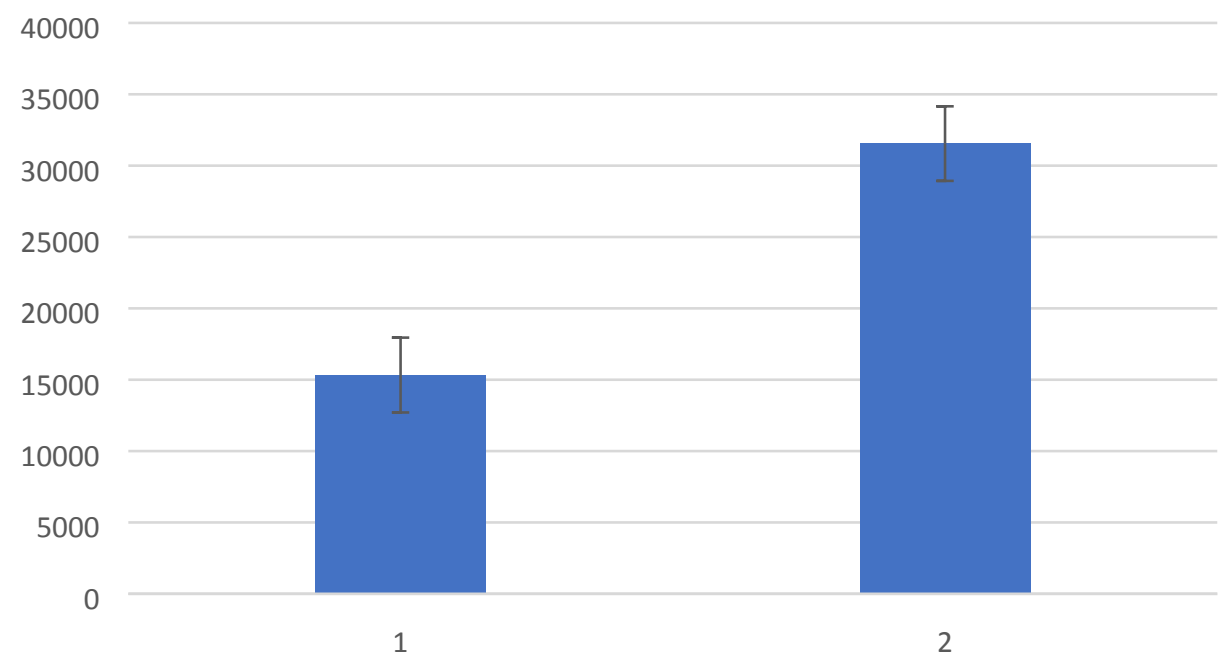

Figure S18: Footprint area analyzed from 35 proteinous residues left behind by detached bacteria on the gradient surfaces functionalized with PEG 5000. Two distinct populations were found, representing cells that were attached as single or duplex. Error bars represent standard deviation. H., Gradients in surface nanotopography used to study platelet adhesion and activation. Colloids Surf B Biointerfaces 2013, 110 (0), 261-9.

2. Lundgren, A.; Hulander, M.; Brorsson, J.; Hermansson, M.; Elwing, H.; Andersson, O.; Liedberg, B.; Berglin, M., Gold-Nanoparticle-Assisted Self-Assembly of Chemical Gradients with Tunable Sub-50 nm Molecular Domains. Particle \& Particle Systems Characterization 2013, n/a-n/a. 